\title{
Strong Convergence of Parallel Iterative Algorithm with Mean Errors for Two Finite Families of Ćirić Quasi-Contractive Operators
}

\author{
Feng Gu \\ Institute of Applied Mathematics and Department of Mathematics, Hangzhou Normal University, \\ Zhejiang, Hangzhou 310036, China \\ Correspondence should be addressed to Feng Gu, gufeng99@sohu.com \\ Received 23 June 2012; Revised 19 August 2012; Accepted 21 August 2012 \\ Academic Editor: Yonghong Yao \\ Copyright (c) 2012 Feng Gu. This is an open access article distributed under the Creative Commons \\ Attribution License, which permits unrestricted use, distribution, and reproduction in any \\ medium, provided the original work is properly cited. \\ The purpose of this paper is to establish a strong convergence of a new parallel iterative algorithm \\ with mean errors to a common fixed point for two finite families of Cirić quasi-contractive \\ operators in normed spaces. The results presented in this paper generalize and improve the \\ corresponding results of Berinde, Gu, Rafiq, Rhoades, and Zamfirescu.
}

\section{Introduction and Preliminaries}

Let $(X, d)$ be a metric space. A mapping $T: X \rightarrow X$ is said to be a-contraction, if $d(T x, T y) \leq$ $a d(x, y)$ for all $x, y \in X$, where $a \in(0,1)$.

The mapping $T: X \rightarrow X$ is said to be Kannan mapping [1], if there exists $b \in(0,1 / 2)$ such that $d(T x, T y) \leq b[d(x, T x)+d(y, T y)]$ for all $x, y \in X$.

A mapping $T: X \rightarrow X$ is said to be Chatterjea mapping [2], if there exists $c \in(0,1 / 2)$ such that $d(T x, T y) \leq c[d(x, T y)+d(y, T x)]$ for all $x, y \in X$. result.

Combining these three definitions, Zamfirescu [3] proved the following important

Theorem $\mathbf{Z}$ (see [3]). Let $(X, d)$ be a complete metric space and $T: X \rightarrow X$ a mapping for which there exist the real numbers $a, b$, and $c$ satisfying $a \in(0,1), b, c \in(0,1 / 2)$ such that for each pair $x, y \in X$, at least one of the following conditions holds:

$$
\left(z_{1}\right) d(T x, T y) \leq \operatorname{ad}(x, y),
$$




$$
\begin{aligned}
& \left(z_{2}\right) d(T x, T y) \leq b[d(x, T x)+d(y, T y)], \\
& \left(z_{3}\right) d(T x, T y) \leq c[d(x, T y)+d(y, T x)] .
\end{aligned}
$$

Then $T$ has a unique fixed point $p$ and the Picard iteration $\left\{x_{n}\right\}$ defined by

$$
x_{n+1}=T x_{n}, \quad n \in \mathbb{N}
$$

converges to $p$ for any arbitrary but fixed $x_{1} \in X$.

Remark 1.1. An operator $T$ satisfying the contractive conditions $\left(z_{1}\right)-\left(z_{3}\right)$ in the above theorem is called Z-operator.

Remark 1.2. The conditions $\left(z_{1}\right)-\left(z_{3}\right)$ can be written in the following equivalent form:

$$
d(T x, T y) \leq h \max \left\{d(x, y), \frac{d(x, T x)+d(y, T y)}{2}, \frac{d(x, T y)+d(y, T x)}{2}\right\},
$$

for all $x, y \in X, 0<h<1$. Thus, a class of mappings satisfying the contractive conditions $\left(z_{1}\right)-\left(z_{3}\right)$ is a subclass of mappings satisfying the following condition:

$$
d(T x, T y) \leq h \max \left\{d(x, y), d(x, T x), d(y, T y), \frac{d(x, T y)+d(y, T x)}{2}\right\}
$$

$0<h<1$. The class of mappings satisfying (CG) is introduced and investigated by Ćirić [4] in 1971.

Remark 1.3. A mapping satisfying (CG) is commonly called Cirić generalized contraction.

In 2000, Berinde [5] introduced a new class of operators on a normed space $E$ satisfying

$$
\|T x-T y\| \leq \rho\|x-y\|+L\|T x-x\|,
$$

for any $x, y \in E, 0 \leq \delta<1$ and $L \geq 0$.

Note that (1.3) is equivalent to

$$
\|T x-T y\| \leq \rho\|x-y\|+L \min \{\|T x-x\|,\|T y-y\|\},
$$

for any $x, y \in E, 0 \leq \rho<1$ and $L \geq 0$.

Berinde [5] proved that this class is wider than the class of Zamfiresu operators and used the Mann [6] iteration process to approximate fixed points of this class of operators in a normed space given in the form of following theorem.

Theorem B (see [5]). Let $C$ be a nonempty closed convex subset of a normed space E. Let $T: C \rightarrow C$ be an operator satisfying (1.3) and $F(T) \neq \emptyset$. For given $x_{0} \in C$, let $\left\{x_{n}\right\}$ be generated by the algorithm

$$
x_{n+1}=\left(1-\alpha_{n}\right) x_{n}+\alpha_{n} T x_{n}, \quad n \geq 0,
$$


where $\left\{\alpha_{n}\right\}$ be a real sequence in $[0,1]$. If $\sum_{n=1}^{\infty} \alpha_{n}=\infty$, then $\left\{x_{n}\right\}_{n=0}^{\infty}$ converges strongly to the unique fixed point of $T$.

In 2006, Rafiq [7] considered a class of mappings satisfying the following condition:

$$
\|T x-T y\| \leq h \max \left\{\|x-y\|, \frac{\|x-T x\|+\|y-T y\|}{2},\|x-T y\|,\|y-T x\|\right\},
$$

$0<h<1$. This class of mappings is a subclass of mappings satisfying the following condition:

$$
\|T x-T y\| \leq h \max \{\|x-y\|,\|x-T x\|,\|y-T y\|,\|x-T y\|,\|y-T x\|\},
$$

$0<h<1$. The class of mappings satisfying (CQ) was introduced and investigated by Ćirić [8] in 1974 and a mapping satisfying is commonly called Ćirić quasi-contraction.

Rafiq [7] proved the following result.

Theorem $\mathbf{R}$ (see [7]). Let $C$ be a nonempty closed convex subset of a normed space E. Let $T: C \rightarrow C$ be an operator satisfying the condition $(C R)$. For given $x_{0} \in C$, let $\left\{x_{n}\right\}$ be generated by the algorithm

$$
x_{n+1}=\alpha_{n} x_{n}+\beta_{n} T x_{n}+\gamma_{n} u_{n}, \quad n \geq 0,
$$

where $\left\{\alpha_{n}\right\},\left\{\beta_{n}\right\}$, and $\left\{\gamma_{n}\right\}$ be three real sequences in $[0,1]$ satisfying $\alpha_{n}+\beta_{n}+\gamma_{n}=1$ for all $n \geq 1$, $\left\{u_{n}\right\}$ is a bounded sequences in $C$. If $\sum_{n=1}^{\infty} \beta_{n}=\infty$ and $\gamma_{n}=o\left(\alpha_{n}\right)$, then $\left\{x_{n}\right\}_{n=0}^{\infty}$ converges strongly to the unique fixed point of $T$.

In 2007, Gu [9] proved the following theorem.

Theorem G (see [9]). Let $C$ be a nonempty closed convex subset of a normed space E. Let $\left\{T_{i}\right\}_{i=1}^{N}$ : $C \rightarrow C$ be $N$ operators satisfying the condition $(C R)$ with $F=\cap_{i=1}^{N} F\left(T_{i}\right) \neq \emptyset$ (the set of common fixed points of $\left.\left\{T_{i}\right\}_{i=1}^{N}\right)$. Let $\left\{\alpha_{n}\right\},\left\{\beta_{n}\right\}$, and $\left\{\gamma_{n}\right\}$ be three real sequences in $[0,1]$ satisfying $\alpha_{n}+\beta_{n}+\gamma_{n}=1$ for all $n \geq 1,\left\{u_{n}\right\}$ a bounded sequences in $C$ satisfying the following conditions:

(i) $\sum_{n=1}^{\infty} \beta_{n}=\infty$;

(ii) $\sum_{n=1}^{\infty} \gamma_{n}<\infty$ or $\gamma_{n}=o\left(\beta_{n}\right)$.

Suppose further that $x_{0} \in C$ is any given point and $\left\{x_{n}\right\}$ is generated by the algorithm

$$
x_{n+1}=\alpha_{n} x_{n}+\beta_{n} T_{n} x_{n}+\gamma_{n} u_{n}, \quad n \geq 0,
$$

where $T_{n}=T_{n(\bmod N)}$. Then $\left\{x_{n}\right\}$ converges strongly to a common fixed point of $\left\{T_{i}\right\}_{i=1}^{N}$.

Remark 1.4. It should be pointed out that Theorem $\mathrm{G}$ extends Theorem $\mathrm{R}$ from a Ćirić quasicontractive operator to a finite family of Cirić quasi-contractive operators. 
Inspired and motivated by the facts said above, we introduced a new two-step parallel iterative algorithm with mean errors for two finite family of operators $\left\{S_{i}\right\}_{i=1}^{m}$ and $\left\{T_{j}\right\}_{j=1}^{k}$ as follows:

$$
\begin{aligned}
& x_{n+1}=\left(1-\alpha_{n}-\gamma_{n}\right) x_{n}+\alpha_{n} \sum_{i=1}^{m} \lambda_{i} S_{i} y_{n}+\gamma_{n} u_{n}, \quad n \geq 1, \\
& y_{n}=\left(1-\beta_{n}-\delta_{n}\right) x_{n}+\beta_{n} \sum_{j=1}^{k} \mu_{i} T_{j} x_{n}+\delta_{n} v_{n}, \quad n \geq 1,
\end{aligned}
$$

where $\left\{\lambda_{i}\right\}_{i=1}^{m},\left\{\mu_{j}\right\}_{j=1}^{k}$ are two finite sequences of positive number such that $\sum_{i=1}^{m} \lambda_{i}=1$ and $\sum_{j=1}^{k} \mu_{j}=1,\left\{\alpha_{n}\right\},\left\{\beta_{n}\right\},\left\{\gamma_{n}\right\}$ and $\left\{\delta_{n}\right\}$ are four real sequences in $[0,1]$ satisfying $\alpha_{n}+\gamma_{n} \leq 1$ and $\beta_{n}+\delta_{n} \leq 1$ for all $n \geq 1,\left\{u_{n}\right\}$ and $\left\{v_{n}\right\}$ are two bounded sequences in $C$ and $x_{0}$ is a given point.

Especially, if $\left\{\alpha_{n}\right\},\left\{\gamma_{n}\right\}$ are two sequences in $[0,1]$ satisfying $\alpha_{n}+\gamma_{n} \leq 1$ for all $n \geq 1$, $\left\{\lambda_{i}\right\}_{i=1}^{m} \subset[0,1]$ satisfying $\lambda_{1}+\lambda_{2}+\cdots+\lambda_{m}=1,\left\{u_{n}\right\}$ is a bounded sequence in $C$ and $x_{0}$ is a given point in $C$, then the sequence $\left\{x_{n}\right\}$ defined by

$$
x_{n+1}=\left(1-\alpha_{n}-\gamma_{n}\right) x_{n}+\alpha_{n} \sum_{i=1}^{m} \lambda_{i} S_{i} x_{n}+\gamma_{n} u_{n}, \quad n \geq 1
$$

is called the one-step parallel iterative algorithm with mean errors for a finite family of operators $\left\{S_{i}\right\}_{i=1}^{m}$.

The purpose of this paper is to study the convergence of two-steps parallel iterative algorithm with mean errors defined by (1.8) to a common fixed point for two finite family of Cirić quasi-contractive operators in normed spaces. The results presented in this paper generalized and extend the corresponding results of Berinde [5], Gu [9], Rafiq [7], Rhoades [10], and Zamfirescu [3]. Even in the case of $\beta_{n}=\delta_{n}=0$ or $\gamma_{n}=\delta_{n}=0$ for all $n \geq 1$ or $m=k=1$ are also new.

In order to prove the main results of this paper, we need the following Lemma.

Lemma 1.5 (see [11]). Suppose that $\left\{a_{n}\right\},\left\{b_{n}\right\}$, and $\left\{c_{n}\right\}$ are three nonnegative real sequences satisfying the following condition:

$$
a_{n+1} \leq\left(1-t_{n}\right) a_{n}+b_{n}+c_{n}, \quad \forall n \geq n_{0}
$$

where $n_{0}$ is some nonnegative integer, $t_{n} \in[0,1], \sum_{n=0}^{\infty} t_{n}=\infty, b_{n}=o\left(t_{n}\right)$ and $\sum_{n=0}^{\infty} c_{n}<\infty$. Then $\lim _{n \rightarrow \infty} a_{n}=0$.

\section{Main Results}

We are now in a position to prove our main results in this paper.

Theorem 2.1. Let $C$ be a nonempty closed convex subset of a normed space $E$. Let $\left\{S_{i}\right\}_{i=1}^{m}: C \rightarrow C$ be $m$ operators satisfying the condition $(C R)$ and $\left\{T_{j}\right\}_{j=1}^{k}: C \rightarrow C$ be $k$ operators satisfying the 
condition $(C R)$ with $F=\left(\bigcap_{i=1}^{m} F\left(S_{i}\right)\right) \cap\left(\bigcap_{j=1}^{k} F\left(T_{j}\right)\right) \neq \emptyset$, where $F\left(S_{i}\right)$ and $F\left(T_{j}\right)$ are the set of fixed points of $S_{i}$ and $T_{j}$ in $C$, respectively. Let $\left\{\alpha_{n}\right\},\left\{\beta_{n}\right\},\left\{\gamma_{n}\right\}$, and $\left\{\delta_{n}\right\}$ be four real sequences in $[0,1]$ satisfying $\alpha_{n}+\gamma_{n} \leq 1$ and $\beta_{n}+\delta_{n} \leq 1$ for all $n \geq 1,\left\{\lambda_{i}\right\}_{i=1}^{m},\left\{\mu_{j}\right\}_{j=1}^{k}$ two finite sequences of positive number such that $\sum_{i=1}^{m} \lambda_{i}=1$ and $\sum_{j=1}^{k} \mu_{j}=1,\left\{u_{n}\right\}$ and $\left\{v_{n}\right\}$ two bounded sequences in $C$ satisfying the following conditions:

(i) $\sum_{n=1}^{\infty} \alpha_{n}=\infty$;

(ii) $\lim _{n \rightarrow \infty} \delta_{n}=0$;

(iii) $\sum_{n=1}^{\infty} \gamma_{n}<\infty$ or $\gamma_{n}=o\left(\alpha_{n}\right)$.

Suppose further that $x_{0} \in C$ is any given point and $\left\{x_{n}\right\}$ is an iteration sequence with mane errors defined by (1.8), then $\left\{x_{n}\right\}$ converges strongly to a common fixed point of $\left\{S_{i}\right\}_{i=1}^{m}$ and $\left\{T_{j}\right\}_{j=1}^{k}$.

Proof. Since $\left\{S_{i}\right\}_{i=1}^{m}: C \rightarrow C$ is $m$ Ćirić operator satisfying the condition (CR), hence there exists $0<h_{i}<1(i \in I=\{1,2, \ldots, m\})$ such that

$$
\left\|S_{i} x-S_{i} y\right\| \leq h_{i} \max \left\{\|x-y\|, \frac{\left\|x-S_{i} x\right\|+\left\|y-S_{i} y\right\|}{2},\left\|x-S_{i} y\right\|,\left\|y-S_{i} x\right\|\right\} .
$$

For each fixed $i \in I=\{1,2, \ldots, m\}$. Denote $h=\max \left\{h_{1}, h_{2}, \ldots, h_{m}\right\}$, then $0<h<1$ and

$$
\left\|S_{i} x-S_{i} y\right\| \leq h \max \left\{\|x-y\|, \frac{\left\|x-S_{i} x\right\|+\left\|y-S_{i} y\right\|}{2},\left\|x-S_{i} y\right\|,\left\|y-S_{i} x\right\|\right\}
$$

hold for each fixed $i \in I=\{1,2, \ldots, m\}$. If from (2.2) we have

$$
\left\|S_{i} x-S_{i} y\right\| \leq \frac{h}{2}\left[\left\|x-S_{i} x\right\|+\left\|y-S_{i} y\right\|\right]
$$

then

$$
\begin{aligned}
\| S_{i} x & -S_{i} y \| \leq \frac{h}{2}\left[\left\|x-S_{i} x\right\|+\left\|y-S_{i} y\right\|\right] \\
& \leq \frac{h}{2}\left[\left\|x-S_{i} x\right\|+\|y-x\|+\left\|x-S_{i} x\right\|+\left\|S_{i} x-S_{i} y\right\|\right] .
\end{aligned}
$$

Hence

$$
\left(1-\frac{h}{2}\right)\left\|S_{i} x-S_{i} y\right\| \leq \frac{h}{2}\|x-y\|+h\left\|x-S_{i} x\right\|,
$$

which yields (using the fact that $0<h<1$ )

$$
\left\|S_{i} x-S_{i} y\right\| \leq \frac{h / 2}{1-h / 2}\|x-y\|+\frac{h}{1-h / 2}\left\|x-S_{i} x\right\|
$$


Also, from (2.2), if

$$
\left\|S_{i} x-S_{i} y\right\| \leq h \max \left\{\left\|x-S_{i} y\right\|,\left\|y-S_{i} x\right\|\right\}
$$

holds, then

(a) $\left\|S_{i} x-S_{i} y\right\| \leq h\left\|x-S_{i} y\right\|$, which implies $\left\|S_{i} x-S_{i} y\right\| \leq h\left\|x-S_{i} x\right\|+h\left\|S_{i} x-S_{i} y\right\|$ and hence, as $h<1$,

$$
\left\|S_{i} x-S_{i} y\right\| \leq \frac{h}{1-h}\left\|x-S_{i} x\right\|
$$

or

(b) $\left\|S_{i} x-S_{i} y\right\| \leq h\left\|y-S_{i} x\right\|$, which implies

$$
\left\|S_{i} x-S_{i} y\right\| \leq h\|y-x\|+h\left\|x-S_{i} x\right\|
$$

Thus, if (2.7) holds, then from (2.8) and (2.9) we have

$$
\left\|S_{i} x-S_{i} y\right\| \leq h\|y-x\|+\frac{h}{1-h}\left\|x-S_{i} x\right\| .
$$

Denote

$$
\rho_{1}=\max \left\{h, \frac{h / 2}{1-h / 2}\right\}=h, \quad L_{1}=\max \left\{h, \frac{h}{1-h / 2}, \frac{h}{1-h}\right\}=\frac{h}{1-h} .
$$

Then we have $0<\rho_{1}<1$ and $L_{1} \geq 0$. Combining (2.2),(2.6), and (2.10) we get

$$
\left\|S_{i} x-S_{i} y\right\| \leq \rho_{1}\|x-y\|+L_{1}\left\|x-S_{i} x\right\|
$$

holds for all $x, y \in C$ and $i \in I$.

On the other hand, since $\left\{T_{j}\right\}_{j=1}^{k}: C \rightarrow C$ is $k$ Cirić operator satisfying the condition (CR), similarly, we can prove

$$
\left\|T_{j} x-T_{j} y\right\| \leq \rho_{2}\|x-y\|+L_{2}\left\|x-S_{i} x\right\|
$$

for all $x, y \in C$ and $j \in J=\{1,2, \ldots, k\}$, where $0<\rho_{2}<1$ and $L_{2} \geq 0$. 
Let $p \in F=\left(\bigcap_{i=1}^{m} F\left(S_{i}\right)\right) \cap\left(\bigcap_{j=1}^{k} F\left(T_{j}\right)\right)$; using (1.8) we have

$$
\begin{aligned}
\left\|x_{n+1}-p\right\| & =\left\|\left(1-\alpha_{n}-\gamma_{n}\right)\left(x_{n}-p\right)+\alpha_{n} \sum_{i=1}^{m} \lambda_{i}\left(S_{i} y_{n}-p\right)+\gamma_{n}\left(u_{n}-p\right)\right\| \\
& \leq\left(1-\alpha_{n}-\gamma_{n}\right)\left\|x_{n}-p\right\|+\alpha_{n} \sum_{i=1}^{m} \lambda_{i}\left\|S_{i} y_{n}-p\right\|+\gamma_{n}\left\|u_{n}-p\right\| \\
& \leq\left(1-\alpha_{n}\right)\left\|x_{n}-p\right\|+\alpha_{n} \sum_{i=1}^{m} \lambda_{i}\left\|S_{i} y_{n}-p\right\|+\gamma_{n} M,
\end{aligned}
$$

where $M=\sup _{n \geq 1}\left\{\left\|u_{n}-p\right\|,\left\|v_{n}-p\right\|\right\}$. Now for $y=y_{n}$ and $x=p$, (2.12) gives

$$
\left\|S_{i} y_{n}-p\right\|=\left\|S_{i} y_{n}-S_{i} p\right\| \leq \rho_{1}\left\|y_{n}-p\right\| .
$$

Substituting (2.15) into (2.14), we obtain that

$$
\left\|x_{n+1}-p\right\| \leq\left(1-\alpha_{n}\right)\left\|x_{n}-p\right\|+\alpha_{n} \rho_{1}\left\|y_{n}-p\right\|+\gamma_{n} M
$$

Again it follows from (1.8) that

$$
\begin{aligned}
\left\|y_{n}-p\right\| & =\left\|\left(1-\beta_{n}-\delta_{n}\right)\left(x_{n}-p\right)+\beta_{n} \sum_{j=1}^{k} \mu_{j}\left(T_{j} x_{n}-p\right)+\delta_{n}\left(v_{n}-p\right)\right\| \\
& \leq\left(1-\beta_{n}-\delta_{n}\right)\left\|x_{n}-p\right\|+\beta_{n} \sum_{j=1}^{k} \mu_{j}\left\|T_{j} x_{n}-p\right\|+\delta_{n}\left\|v_{n}-p\right\| \\
& \leq\left(1-\beta_{n}\right)\left\|x_{n}-p\right\|+\beta_{n} \sum_{j=1}^{k} \mu_{j}\left\|T_{j} x_{n}-p\right\|+\delta_{n} M .
\end{aligned}
$$

Now for $y=x_{n}$ and $x=p,(2.13)$ gives

$$
\left\|T_{j} x_{n}-p\right\|=\left\|T_{j} x_{n}-T_{j} p\right\| \leq \rho_{2}\left\|x_{n}-p\right\| .
$$

Combining (2.17) and (2.18) we get

$$
\left\|y_{n}-p\right\| \leq\left[1-\beta_{n}\left(1-\rho_{2}\right)\right]\left\|x_{n}-p\right\|+\delta_{n} M \leq\left\|x_{n}-p\right\|+\delta_{n} M
$$

Substituting (2.19) into (2.16), we obtain that

$$
\begin{aligned}
\left\|x_{n+1}-p\right\| & \leq\left(1-\alpha_{n}\right)\left\|x_{n}-p\right\|+\alpha_{n} \rho_{1}\left(\left\|x_{n}-p\right\|+\delta_{n} M\right)+\gamma_{n} M \\
& =\left[1-\alpha_{n}\left(1-\rho_{1}\right)\right]\left\|x_{n}-p\right\|+\alpha_{n} \delta_{n} \rho_{1} M+\gamma_{n} M \\
& =\left(1-t_{n}\right)\left\|x_{n}-p\right\|+b_{n}+c_{n}
\end{aligned}
$$


where

$$
t_{n}=\alpha_{n}\left(1-\rho_{1}\right), \quad b_{n}=\alpha_{n} \delta_{n} \rho_{1} M, \quad c_{n}=\gamma_{n} M
$$

or

$$
t_{n}=\alpha_{n}\left(1-\rho_{1}\right), \quad b_{n}=\alpha_{n} \delta_{n} \rho_{1} M+\gamma_{n} M, \quad c_{n}=0 .
$$

From the conditions (i)-(iii) it is easy to see that $t_{n} \in[0,1], \sum_{n=1}^{\infty} t_{n}=\infty, b_{n}=o\left(t_{n}\right)$, and $\sum_{n=1}^{\infty} c_{n}<\infty$. Thus using (2.20) and Lemma 1.5 we have $\lim _{n \rightarrow \infty}\left\|x_{n}-p\right\|=0$, and so $\lim _{n \rightarrow \infty} x_{n}=p$. This completes the proof of Theorem 2.1.

Theorem 2.2. Let $C$ be a nonempty closed convex subset of a normed space $E$. Let $\left\{S_{i}\right\}_{i=1}^{m}: C \rightarrow C$ be $m$ operators satisfying the condition (2.12) and let $\left\{T_{j}\right\}_{j=1}^{k}: C \rightarrow C$ be $k$ operators satisfying the condition (2.13) with $F=\left(\bigcap_{i=1}^{m} F\left(S_{i}\right)\right) \cap\left(\bigcap_{j=1}^{k} F\left(T_{j}\right)\right) \neq \emptyset$, where $F\left(S_{i}\right)$ and $F\left(T_{j}\right)$ are the set of fixed points of $S_{i}$ and $T_{j}$ in $C$, respectively. Let $\left\{\alpha_{n}\right\},\left\{\beta_{n}\right\},\left\{\gamma_{n}\right\}$, and $\left\{\delta_{n}\right\}$ be four real sequences in $[0,1]$ satisfying $\alpha_{n}+\gamma_{n} \leq 1$ and $\beta_{n}+\delta_{n} \leq 1$ for all $n \geq 1,\left\{\lambda_{i}\right\}_{i=1}^{m},\left\{\mu_{j}\right\}_{j=1}^{k}$ two finite sequences of positive number such that $\sum_{i=1}^{m} \lambda_{i}=1$, and $\sum_{j=1}^{k} \mu_{j}=1,\left\{u_{n}\right\}$ and $\left\{v_{n}\right\}$ two bounded sequences in $C$ satisfying the following conditions:

(i) $\sum_{n=1}^{\infty} \alpha_{n}=\infty$;

(ii) $\lim _{n \rightarrow \infty} \delta_{n}=0$;

(iii) $\sum_{n=1}^{\infty} \gamma_{n}<\infty$ or $\gamma_{n}=o\left(\alpha_{n}\right)$.

Suppose further that $x_{0} \in C$ is any given point and $\left\{x_{n}\right\}$ is an iteration sequence defined by (1.8), then $\left\{x_{n}\right\}$ converges strongly to a common fixed point of $\left\{S_{i}\right\}_{i=1}^{m}$ and $\left\{T_{j}\right\}_{j=1}^{k}$.

Theorem 2.3. Let $C$ be a nonempty closed convex subset of a normed space $E$. Let $\left\{S_{i}\right\}_{i=1}^{m}: C \rightarrow C$ be $m$ operators satisfying the condition $(C R)$ with $F=\bigcap_{i=1}^{m} F\left(S_{i}\right) \neq \emptyset$ (the set of common fixed points of $\left.\left\{S_{i}\right\}_{i=1}^{m}\right)$. Let $\left\{\alpha_{n}\right\}$ and $\left\{\gamma_{n}\right\}$ be two real sequences in $[0,1]$ satisfying $\alpha_{n}+\gamma_{n} \leq 1$ for all $n \geq 1$, $\left\{\lambda_{i}\right\}_{i=1}^{m}$ a finite sequence of positive number such that $\sum_{i=1}^{m} \lambda_{i}=1$, and $\left\{u_{n}\right\}$ a bounded sequence in $C$ satisfying the following conditions:

(i) $\sum_{n=1}^{\infty} \alpha_{n}=\infty$;

(ii) $\sum_{n=1}^{\infty} \gamma_{n}<\infty$ or $\gamma_{n}=o\left(\alpha_{n}\right)$.

Suppose further that $x_{0} \in C$ is any given point and $\left\{x_{n}\right\}$ is an iteration sequence with mane errors defined by (1.9), then $\left\{x_{n}\right\}$ converges strongly to a common fixed point of $\left\{S_{i}\right\}_{i=1}^{m}$.

Theorem 2.4. Let $C$ be a nonempty closed convex subset of a normed space $E$. Let $\left\{S_{i}\right\}_{i=1}^{m}: C \rightarrow C$ be $m$ operators satisfying the condition (2.12) with $F=\bigcap_{i=1}^{m} F\left(S_{i}\right) \neq \emptyset$ (the set of common fixed points of $\left.\left\{S_{i}\right\}_{i=1}^{m}\right)$. Let $\left\{\alpha_{n}\right\}$ and $\left\{\gamma_{n}\right\}$ be two real sequences in $[0,1]$ satisfying $\alpha_{n}+\gamma_{n} \leq 1$ for all $n \geq 1$, $\left\{\lambda_{i}\right\}_{i=1}^{m}$ a finite sequence of positive number such that $\sum_{i=1}^{m} \lambda_{i}=1$, and $\left\{u_{n}\right\}$ a bounded sequence in $C$ satisfying the following conditions:

(i) $\sum_{n=1}^{\infty} \alpha_{n}=\infty$;

(ii) $\sum_{n=1}^{\infty} \gamma_{n}<\infty$ or $\gamma_{n}=o\left(\alpha_{n}\right)$. 
Suppose further that $x_{0} \in C$ is any given point and $\left\{x_{n}\right\}$ is an iteration sequence defined by (1.9), then $\left\{x_{n}\right\}$ converges strongly to a common fixed point of $\left\{S_{i}\right\}_{i=1}^{m}$.

Corollary 2.5 (see [7]). Let $C$ be a nonempty closed convex subset of a normed space E. Let $T: C \rightarrow$ $C$ be an operators satisfying the condition (CR). Let $\left\{\alpha_{n}\right\},\left\{\beta_{n}\right\}$, and $\left\{\gamma_{n}\right\}$ be three real sequences in $[0,1]$ satisfying $\alpha_{n}+\beta_{n}+\gamma_{n}=1$ for all $n \geq 1$ and $\left\{u_{n}\right\}$ a bounded sequences in $C$ satisfying the following conditions:

(i) $\sum_{n=1}^{\infty} \beta_{n}=\infty$;

(ii) $\sum_{n=1}^{\infty} \gamma_{n}<\infty$ or $\gamma_{n}=o\left(\beta_{n}\right)$.

Suppose further that $x_{0} \in C$ is any given point and $\left\{x_{n}\right\}$ is an explicit iteration sequence as follows:

$$
x_{n+1}=\alpha_{n} x_{n}+\beta_{n} T x_{n}+\gamma_{n} u_{n}, \quad n \geq 1,
$$

then $\left\{x_{n}\right\}$ converges strongly to the unique fixed point of $T$.

Proof. By Ćirić [8], we know that $T$ has a unique fixed point in $C$. Taking $m=1$ in Theorem 2.3, then the conclusion of Corollary 2.5 can be obtained from Theorem 2.3 immediately. This completes the proof of Corollary 2.5 .

Remark 2.6. Theorems 2.2-2.4 and Corollary 2.5 improve and extend the corresponding results of Berinde [5], Gu [9], Rafiq [7], Rhoades [10], and Zamfirescu [3].

\section{Acknowledgments}

The present study was supported by the National Natural Science Foundation of China $(11071169,11271105)$ and the Natural Science Foundation of Zhejiang Province (Y6110287, Y12A010095).

\section{References}

[1] R. Kannan, "Some results on fixed points," Bulletin of the Calcutta Mathematical Society, vol. 60, pp. 71-76, 1968.

[2] S. K. Chatterjea, "Fixed-point theorems," Comptes Rendus de l'Académie Bulgare des Sciences, vol. 25, no. 6, pp. 727-730, 1972.

[3] T. Zamfirescu, "Fix point theorems in metric spaces," Archiv der Mathematik, vol. 23, no. 1, pp. 292-298, 1972.

[4] L. B. Ćirić, "Generalized contractions and fixed point theorems," Publications de l'Institut Mathématique, vol. 12, no. 26, pp. 19-26, 1971.

[5] V. Berinde, Iterative Approximation of Fixed Points, Efemeride, Baia Mare, Romania, 2000.

[6] W. R. Mann, "Mean value methods in iteration," Proceedings of the American Mathematical Society, vol. 4, pp. 506-510, 1953.

[7] A. Rafiq, "Fixed points of Ćirić quasi-contractive operators in normed spaces," Mathematical Communications, vol. 11, no. 2, pp. 115-120, 2006.

[8] L. B. Ćirić, "A generalization of Banach's contraction principle," Proceedings of the American Mathematical Society, vol. 45, no. 2, pp. 267-273, 1974.

[9] F. Gu, "Strong convergence of an explicit iterative process with mean errors for a finite family of Cirić quasi-contractive operators in normed spaces," Mathematical Communications, vol. 12, no. 1, pp. 75-82, 2007. 
[10] B. E. Rhoades, "Fixed point iterations using infinite matrices," Transactions of the American Mathematical Society, vol. 196, pp. 161-176, 1974.

[11] S. S. Chang, Y. J. Cho, and H. Y. Zhou, Iterative Methods for Nonlinear Operator Equations in Banach Spaces, Nova Science, New York, NY, USA, 2002. 


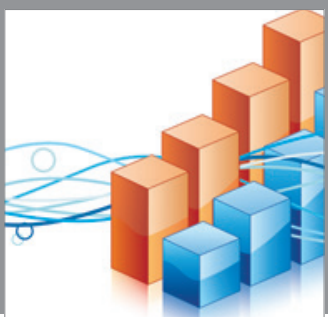

Advances in

Operations Research

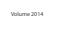

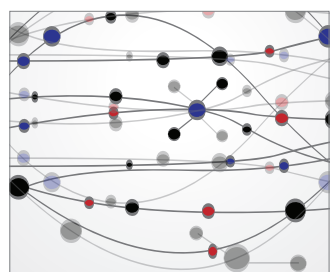

\section{The Scientific} World Journal
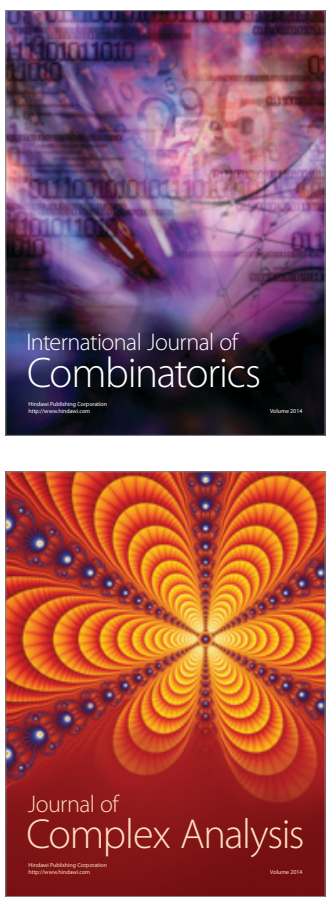

International Journal of

Mathematics and

Mathematical

Sciences
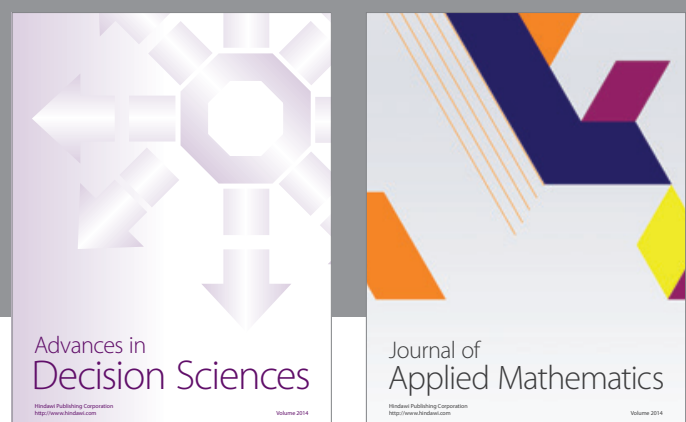

Journal of

Applied Mathematics
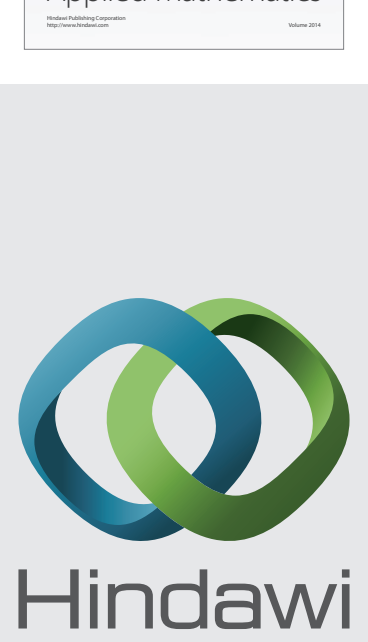

Submit your manuscripts at http://www.hindawi.com
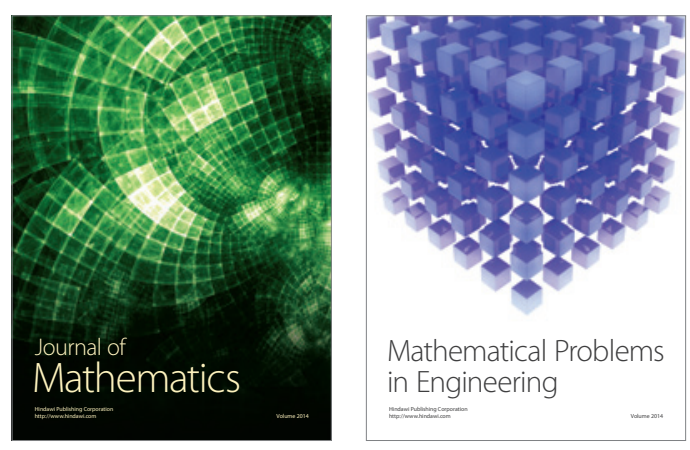

Mathematical Problems in Engineering
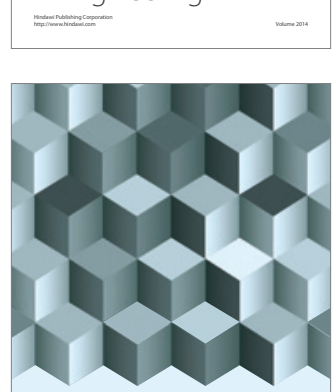

Journal of

Function Spaces
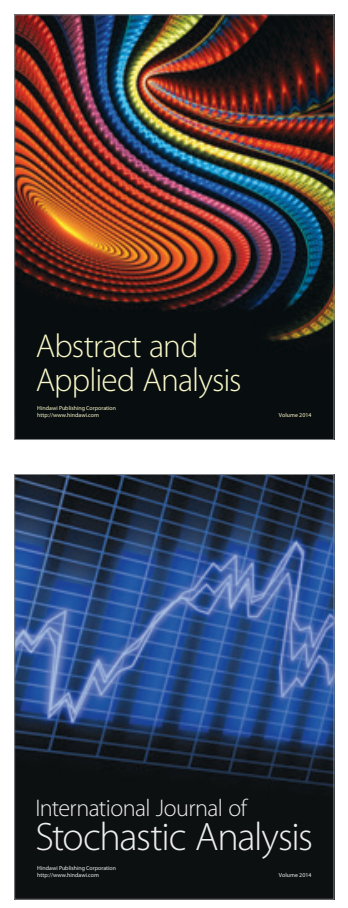

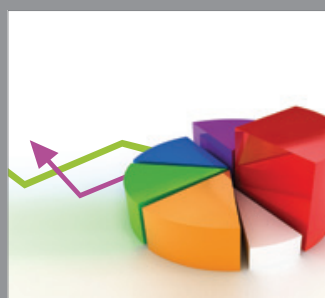

ournal of

Probability and Statistics

Promensencen
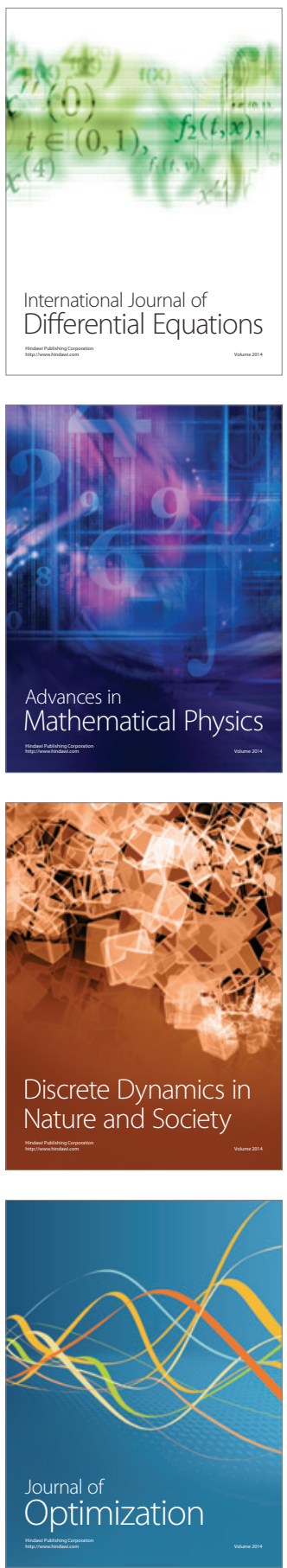